\title{
Vientisinio sakinio skiriamųjų ženklų vartojimas XIX a. vidurio lietuviškuose raštuose: vienarūšès ir aiškinamosios sakinio dalys
}

\author{
LAIMUTÉ BUČIENĖ \\ Lietuvos edukologijos universitetas, T. Ševčenkos g. 31, LT-03111 Vilnius \\ El. paštas: laimute.buciene @vpu.lt
}

\begin{abstract}
Straipsnyje nagrinejjami vientisinio sakinio sintaksinių vienetų - vienarūšiu ir aiškinamujų sakinio dalių - skyrybos ypatumai XIX a. vidurio lietuviškuose raštuose. Šių sakinio dalių skyrybos dèsningumams aptariamojo laikotarpio rašomojoje kalboje nustatyti buvo pasirinkti Mikalojaus Akelaičio, Juozo Silvestro Dovydaičio, Motiejaus Valančiaus, Henriko Balevičiaus ir Kazimiero Michnevičiaus-Mikèno originalūs ir verstiniai prozos veikalai. Atliktas tyrimas atskleidè, kad XIX a. vidurio lietuvių raštijoje ima formuotis apibrèžtesnè ir nuoseklesne vienarūšių ir aiškinamųjų sakinio dalių skyrybos sistema, jau matomi norminès skyrybos pradmenys (neretai skyryba labai šiuolaikiška), nors dar pasitaiko svyravimų ir nevienodumų.
\end{abstract}

Raktažodžiai: XIX a. lietuviški raštai, skyryba, vienarūšès sakinio dalys, aiškinamosios sakinio dalys

\section{IVADAS}

Dabartinè mūsų skyryba turi savo ištakas. Tai istoriškai susiformavęs rašomosios kalbos elementas. Lietuvių kalbos skyrybos istorija iki šiol nedaug tyrinèta, nors ji ir turi beveik penkių amžių tradiciją. Trūksta sisteminių lietuvių kalbos skyrybos raidos tyrimų. Lietuvių kalbos istorijos darbuose tik bendrais bruožais aptariama, kaip buvo vartojami skyrybos ženklai senuosiuose raštuose. Jonas Palionis teigia, kad XVI-XVII a. lietuvių rašomosios kalbos skyrybos sistema buvo labai nenusistovejjusi [5, 35]. Virginija Vasiliauskienè, tirdama Mykolo Olševskio Bromos atvertos ing viečnastį (1753) ir Kiprijono Lukausko Pamokslu (1797) atributinių frazių žodžių tvarką, atkreipia dèmesị ir ị šių tekstų ịvairuojančią, klaidinančią skyrybą $[9,62,65]$. Sunkumų lietuviškų raštų autoriams kilo todèl, kad XVI-XIX a. skyrybos taisyklès nebuvo nustatytos. Pastovesnių skyrybos dėsnių nebūta nei vokiškuose, nei lenkiškuose raštuose, kurie buvo verčiami i lietuvių kalbą ir, matyt, turejo nemažos ịtakos vertèjams. Lietuvių kalbos skyrybos kodifikavimas pradètas Jono Jablonskio darbuose $[8,8 ; 3,585 ; 2,6]$. 
Šio straipsnio tikslas yra išnagrinèti ir apibendrinti XIX a. vidurio rašomojoje kalboje vyravusias vienarūšių ir aiškinamųjų sakinio dalių skyrybos tendencijas. Aptariamojo laikotarpio lietuviškų raštų skyryba specialiai netirta. Atliktos analizès duomenys gali būti pravartūs tiriant kitus skyrybos plètotès etapus. Mèginant nustatyti skyrybos pokyčių kryptị, nagrinejjama, koks jos santykis su dabartinès skyrybos normomis. Tyrimui buvo pasirinkti penki didaktinio ir religinio turinio prozos veikalai: trys originalūs tekstai (M. Akelaičio Kwestorius po Lietuwa ważinedamas žmonis bemokinąsis, 1860; J. S. Dovydaičio Sziauleniszkis senelis, pirma dalis, 1863; M. Valančiaus Wajku kningiele su abrozdelejs: su abrozdelejs, 1868) ir du verstiniai tekstai iš lenkų kalbos (H. Balevičiaus Kielawiedis, 1857; K. Michnevičiaus-Mikèno Szwentas Izydorius artojas, 1859). Pasirinkti tyrimo šaltiniai yra tinkami reprezentuoti XIX a. vidurio rašomosios kalbos būklę, nes tekstų autoriai išsilavinę žmonès, žymūs ano meto kultūros veikèjai, rašytojai, vertèjai. Tyrimo duomenų bazę sudaro 1794 vienarūšių ir aiškinamųjų sakinio dalių skyrybos atvejai. Toks kiekis leidžia susidaryti gana platų vaizdą apie minètų šaltinių skyrybą. Tyrimui panaudotas aprašomasis metodas derinant kiekybinę ir kokybinę duomenų analizę.

\section{VIENARŪŠĖS SAKINIO DALYS}

XIX a. vidurio rašomojoje kalboje, kaip ir dabartinejje kalboje, vienarūšių sakinio dalių skyryba priklausė nuo to, kokiu būdu jos tarpusavyje sujungtos. Tiriamų autorių raštuose gana nuosekliai kableliu atskiriamos vienarūšès sakinio dalys, kai tarp jų nėra jungtuko, pvz.:

Kłausytie kłause budawo tewaj, brolis ir seseres Jono, kad jis parważewęs ant kaledu ar welyku pasakoja jiemis pasakas apej galybę Diewo <...>. Akel 8. Klebonas ne karta draude, bare, moke sakidams: bijokis Diewa Łaurinaj, gal pakarotie už tokius darbus. Dovyd 10. Mosiedi parakwijoj Szakalu sodoj iszsigime wajkielis wardu Mikie labaj guwus, szarpus, pasząnkus ir linksmus. Val 17. Jausk pac ing sawi, padiwijmu, pagayleimu; padiwijmu nietyktey ant kuntribies Wieszpaties, biet ir ant piktibies assirijusiu. Balev 35. Argi ne gałetu pasilinksminti be nusideima, wieżliwaj, grażej, padorej? Michnev 40.

Pavieniais atvejais skyrybos ženklas nededamas, pvz.:

Audraj praslinkus suseje ukinikaj, surinka pardegusius kaułus sudieje i wiena graba, pakiele budinę ir dajlej pałajdoje. Val 5. Pakajus linksmibe, łajswe, giwena, szirdi ja ir rejszkias unt ja wejda. Michnev 19.

Artimos reikšmės bei kartojamụjų žodžių skyryba dvejopa: (a) neskiriama arba (b) atskiriama, suprantant juos kaip vienarūšes sakinio dalis, pvz.:

(a) Noriu gieydziu, priżadu szwintay wieray Rimska-Katalickay, giwient' ir numirt'. Balev 71. $<\ldots>$ tu tarpu kiti dasižinojen apie taj sakis: kad wena antra pakaroje Diewas, taj ir mani gal pakarotie, jajgu ne taja taj su kita rikszti, jejgu ne ant szio, taj ant kito swieto. Dovyd 36. Žmones ant łauka dirbantis pradeje szauktie: žmogau degi degi! Dovyd 36.

(b) <..> Szwintas, Szwintas, Szwintas Wieszpats Diewa galibiu. Balev 66. Pradek tik tikrajkamuotis, a kad ne ażu wiena karta, tej pamażu, pamażu, ne palaudamas pasitikeima Diewu, wisa tau pasiwes. Michnev 9. O atmenu, atmenu, atsiliepe Jurgis, ape Lepiszkius łabaj gili rawaj. Dovyd 35. 
Atkreiptinas dèmesys ị tai, kad tik M. Valančiaus nagrinėjamame tekste bejungtukiu santykiu susietoms vienarūšèms sakinio dalims atskirti neretai yra vartojamas ne tik kablelis, bet ir kabliataškis. Dažniausiai kabliataškis pasirenkamas tada, kai jau bent vienoje jų yra kablelis, pvz.:

Gan buwa sargalotas, wejda iszblieszkuse, płaukielu battu; dajlus bet sitpnus. Val 66. Ritajs, wakarajs, siedant ir kiełantes nu walgie; kalbina poterus. Val 89.

Kabliataškiai meistriškai ịpinami ị ilgesnius sakinius, pvz.:

Ilgajniu Ludwi pramoka: marszkinius surieszti ir pasiuti, jupeles kirpti ir siuti; źekes su pirsztiniemis nerti, płonaj ir djlej werpti, apmesti audikłus, marginius, dwinitius, trinikius, deszimtnitius, zwilikus, abrusus, kilimus ir kiecius aust. Val 84. O nusimanydamas tąnkiej negieraj meldęns; eje wieł spawiednes, su karstu smirdi, su gausiomis aszaromis pirma karta prijeme szwęncziausi sakramenta ir wieł nupelne milesta Wieszpaties. Val 68.

Nors kabliataškiu tiesiog keičiamas kablelis, M. Valančiaus sakinio struktūrai jis suteikia savitumo, papildomų niuansų - sakinys tarsi akimirkai nutraukiamas, paskui vèl tęsiama mintis.

Tyrimo duomenys rodo, kad bejungtukių vienarūšių sakinio dalių skyryba jau tada buvo nusistovejjusi: J. S. Dovydaičio, H. Balevičiaus ir M. Akelaičio tekstuose jos visada atskiriamos, K. Michnevičiaus-Mikèno tekste atskiriama 98 \%, M. Valančiaus - $97 \%$ visų bejungtukių vienarūšių sakinio dalių.

Vienarūšes sakinio dalis, kurios sujungtos priešinamaisiais ar poriniais jungtukais, taip pat dažniausiai linkstama atskirti kableliu (a) (K. Michnevičiaus-Mikèno tekste šie atvejai sudaro 96 \%, J. S. Dovydaičio - 88 \%, M. Akelaičio - 86 \%, M. Valančiaus - 81 \% visų priešinamaisiais ar poriniais jungtukais sujungtų sakinio dalių; H. Balevičiaus raštuose tokiu būdu sujungtos vienarūšès sakinio dalys visada atskiriamos), gerokai rečiau nerašomas joks skyrybos ženklas (b), pvz.:

(a) Netoli Kauno gyweno wienas gaspadorius nebagotas, ala ir nepawargęs. Akel 5. Wenas czinikas ne tiktaj pri żidu begdawa gertie, bet ir namon parsiweże buteli aretkos. Dovyd 7. Wajkaj koźnas sawa bałsu szaukie, tecziaus giedoje. Val 8. Stuptełek czie mażuke, ir iszmig stipriey tawa pamietiy, idant niedel akiu żmaniszku, biet diel paties Diewa, ażu bałsa cnatas ir tieysibies, wissomt waykszcziatum, pabeygay dok priżadiejmu, jog diel prietielistes, łoskas, arbo kokiu dawanu, niekadu tieysibies nieapleysi. Balev 41. Del ta Izydorius jau czia unt żiames jaute tikru pakaju, a tajp ir tikru tajmi. Michnev 6.

(b) Ne walna, mana wajks tieszities isz swetimos biedos; kas paklides grinszta ant gera kela tan milet rejk_o ne parsakiotie. Dovyd 40. Zarienu parakwijoj buwa bajorajtis wajkiukas niekuo nedietas bet plikis. Val 42. Perstodamas unt paszaukima sawa, ne murmeja, nej raudoja, nesisikunde pria wisu sunkiausi darbu, bet tikraj ir isz szirdies Ponu sawa tarnawa, ne kajp żmonems. bet kajp Diewu tarnaudamas. Michnev 24.

M. Valančiaus analizuojamuose raštuose pasitaiko vienas kitas atvejis, kai prieš jungtuką bet, jungiantị vienarūšes sakinio dalis, rašomas ne kablelis, o kabliataškis ar net dvitaškis, pvz.: 
Sekdamas ju pawejzda, norieje sawi płakti; bet negalieje nu kitu pasislepti. Val 94. Todieł wajkaj mana niekuomet nbijokieties niekokiu dwasiu: bet nugąnstaukiet; szunu, witku o uź wis piktu źmoniu. Val 80.

Visuose tekstuose ryškiai vyrauja polinkis neatskirti nekartojamaisiais jungtukais ir, arba, ar sujungtų vienarūšių sakinio dalių, pvz.:

O gajta seniuj buwo tokio jauno ir mokyto wyro. Akel 18. Da ne sutemus bije ejtie darżinen arba jaujon, regies jam kad pikta dwase nagus iszplietus stowi uż duru ir tiko jam dusze iszpliesztie. Dovyd 8. Pagalaus daktara ir kuniga westi gawa. Val 47. Wienam sutejk tokię doribę arba cnatą, kitam kitokię pagat sawa tiksta. Val 37. Tosne kielos, idant niewilatum arbo niebłuditum, a żinotum kur kokies małdes turi prawiniet, ir kiek użtrukt diel abturieima waysious gaysia zostugu Jezusa Pona, paimk szitu Knigieły ażu Kielawiedi. Balev 7. Ponu, tieyp ir tu Judasziskey ar niebuczioi, kad mieldes, kad griekosne unt kamuniju prieyni <...>. Balev 18. Tau Cherubiney $\underline{\text { r }}$ Serafiney nołatiniu bałsu szaukie <...>. Balev 66. Tej tu łabjaus bijej żmoniu ir sarmatijas, kajp pates Diewa? Michnev 10.

Analizuojami šaltiniai liudija, kad tik mažą dalị (J. S. Dovydaičio tekste $3 \%$, M. Akelaičio - $16 \%$, H. Balevičiaus - $18 \%$, K. Michnevičiaus-Mikèno - $21 \%$ ) sudaro tokie skyrybos atvejai, kai kablelis dedamas tarp nekartojamuoju sudedamuoju ar skiriamuoju jungtuku sujungtų vienarūšių sakinio dalių, pvz.:

Isz to atsake Adomene, mes wakar namus dabojem, o szindi pałikom sawa dukteris, arba szejminikszti, o paczes atejem pakłausitie tamstos. Dovyd 45. Pernakwojojęs Jonas ir padekawojęs gaspadoriuj uż pawajszima, toliaus kelawo, ir tiesiok ant pietu użważewo pas kuniga plebona, kuris buwo jo mokytoju. Akel 61. Nog tas wietas, par wissu żigi, ir wisses bromes, katras pakiełuy matisi niet unt Piłatu, ne apłeysk mislas nabażnas ir akiu iż Pona Jezusa, par tos wissus kielus tussita. Balev 34-35. Sapieha, tieypagi Biskupas Wileńskas, pabeygis tos kielus, pariedkawat, paszwintie, iszstatie bażnicziu Wierkosie pa wardu szwinta Kriżieus ir iższwintie ju, arba pakonsekrawaja. Balev 7. Nieacikiełs niezbażni ant suda wagul psalmistas, niey griesznikey draugien tieysingu; nusgusk ta suda, ta nupolima, a połunt dabar priesz Jezusu aciduksek taridamas: $\langle\ldots>$. Balev 51. <...> kad szwentaj dienaj didesniu jam garbi ir szłowi ataduotutumem, garbindami ażu perejtu nedełu, a metsdami padeima unt atejnunczias. Michnev 27.

Reikia pabrèžti, kad M. Valančiaus raštuose nekartojamaisiais jungtukais sujungtų vienarūšių sakinio dalių skyryba yra visada nuosekli - šios sakinio dalys neskiriamos.

Kartojamaisiais jungtukais sujungtų vienarūšių sakinio dalių skyrybai dar trūksta nuoseklumo: vienur jos atskiriamos kableliais (a) (H. Balevičiaus tekste šie atvejai sudaro $60 \%$, K. Michnevičiaus-Mikèno - 50 \%, J. S. Dovydaičio - 42 \%, M. Akelaičio - 57 \%, M. Valančiaus - $48 \%$ visų kartojamaisiais jungtukais sujungtų vienarūšių sakinio dalių), kitur - ne (b), pvz.:

(a) Nors cze wis grażu ir padoru, moteris użpeczki siedż ant kedełu ir zosłanu, wiraj skirim ant solu, bet mażiukaj tie pej duris szwiesaj użgesus arba snaudż, arba wiens kita pesziodami juokus dara. Dovyd 20. Pawasariuj isztikus paukszteliaj gieda, gywuleliaj bliauna, żirgeliaj żwengia - wisas pasaulis dżiaugesi sułaukęs sziłumos; o betgi nej pauksztelis, nej jautis arielką 
geria... Akel 40. Nej numirielej, nej ju dusies, nej welnias pats gał bajditi źmoniu. Val 80. A tey wissa keyp kuntrus, keyp sawa muczytajem pawatnas buwa Ponas Jezus. Balev 58. Kajp tiktaj Jzydorius kałbeti pradeja, jau ir parsiżegnoti mokieja, 푸 poterelus sawa kas rita ir wakara katbeja, garbindamas Diewu ażu aptureretas geradeistes, ir nauju małsdamas. Michnev 11.

(b) Żids pażiurejes jam i akis tare: ar isztiesu sakajar tik żertawoj waszec? Dovyd 35. Asz żinau kajp elgesi kantrabandieriaj - kartajs_ir arkli pawagia ir żmogu użmusza ... Akel 27. Bet patiudu budamu nemokitu ir wajka neiszmokie nej raszta nej lankiszkaj. Val 42. <..> praszam tawies, palik tugi żinkłu pamietiy ir szirdiy mussu, idant jo, ir sziem giwenim ir amżious passitieszit gałetum. Balev 50. <...> szw: Izydoriaus Arcywiskupa miesta Sewillas, użtaritoja musu Izydoriaus, katra paminkłu ir ijs ir ja tewaj garbina ir miteja <...>. Michnev 20.

Atliktas vienarūšių sakinio dalių skyrybos tyrimas atskleidė, kad aptariamuoju laikotarpiu šios sakinio dalys atskiriamos arba neskiriamos palyginti dėsningai. Formuojasi rašto praktika atskirti bejungtukes ir priešinamaisiais ar poriniais jungtukais sujungtas vienarūšes sakinio dalis, nedèti skiriamojo ženklo tarp nekartojamuoju sudedamuoju ir skiriamuoju jungtuku sujungtų vienarūšių sakinio dalių. Daugiausia ịvairuoja kartojamaisiais jungtukais sujungtų vienarūšių sakinio dalių skyryba.

\section{AIŠKINIMAS}

Aiškinimo sąvokos apibrèžtis lietuvių kalbos skyrybos aprašuose skiriasi. Vienur atskirai kalbama apie sakinio dalių aiškinamąją ir tikslinamąją paskirtị [7, 15-20], kitur aptariami tik aiškinamųjų sakinio dalių santykiai $[4,154-165 ; 6,25]$. Šiame straipsnyje aiškinimas suprantamas plačiai - i jo sąvokos turinị ịtraukiamas ir tikslinimas [plg. 1, 3].

Analizuojamuose XIX a. vidurio spaudiniuose didžioji dalis vienavardžių sakinio dalių be jungiamųjų žodžių yra išskiriama kableliais, siekiant parodyti aiškinamąją jų funkciją (M. Akelaičio tekste išskiriama $98 \%$ visų aiškinamųjų sakinio dalių be jungiamųjų žodžių, J. S. Dovydaičio - 94 \%, H. Balevičiaus - 97 \%, K. Michnevičiaus-Mikèno $96 \%)$, pvz.:

$<\ldots . .>$ turi sopuli unt duszias, sopuli mirtina nusideima, ir ne ejni unt tuo dungiszku daktaru, idant tawi iszgiditu <...>. Michnev 64. Isz tu dwieju kiłsta Liełupe, kuri perbegusi Kurżemius, greta su Daugawa teka in Baltasias juras, netoli Rygos. Akel 23. Bet ape taj kita karta pasikalbesme, dabar tik norejau primintie kas atsitika Telsziu parapijo, arti baniczeles Wieszwieniu. Dovyd 37. <...> pamatis więtu, pridieruncziu, ażu pusmila nog Wilnious, ant katnu Werkowsku, lepie kielus mukas Chrystusa iszwiest ir iszmierot <...>. Balev 6.

Tik K. Michnevičiaus-Mikėno tekste rastas atvejis, kai aiškinamoji sakinio dalis (aiškinamasis pažyminys) išskiriama brūkšniais, kurie žymi pabrèžiamąją intonaciją:

Niekas niekamet ne mate Izydoriaus supikusia wejda - su pakiltajs isz siutima ptaukajs - unt kaktas juo wisadu buwa linksmibe, a burna juokinga <...>. Michnev 46.

M. Akelaičio, J. S. Dovydaičio, H. Balevičiaus ir K. Michnevičiaus-Mikėno raštuose aptikta labai nedaug sakinių, kai aiškinamosios sakinio dalys neišskiriamos, pvz.: 
O su kokiu buwa nuometu, pakłause Marike, bene namu darba su raudonajs krasztajs? Dovyd 33. Taj tewelis ir paketino nuweżtie sawo suneli in miesta pas kunigą klebona. Akel 7. $<\ldots>$ atejna isz neżiniu isz toła liggota seneła małdaudama susimiłejma. Michnev 61. Ir jus szwintiei Apaształey, Makitiniey Jezusa, nars iż silpnibies zmaniszkas, toczies draugiey niekielawat, padiekit mań dabar, jou dwasiu szwintu pastiprinti, szirdin mana inpilkit dwasiu <...>. Balev 12. Tawi Diewie garbinam, tawi Wieszpati iżpażistam. Balev 6.

Atskirai paminètina, kad M. Valančiaus nagrinėjamame tekste aiškinamosios sakinio dalys be jungiamųjų žodžių niekada neskiriamos, pvz.:

Pałagos parakwijoj Kunegiszkiu sodoj giwena Jonas pipkinikas. Val 35. Tyrkszlu parakwijoj Spurganu sodoj giwena źmogus wardu Pilipas. Val 76.

Tiriamojoje medžiagoje rasta tik po kelis atvejus, kai (a) aiškinamoji sakinio dalis turi jungiamajj žodị, (b) kelios aiškinamosios sakinio dalys eina po apibendrinamojo žodžio ir (c) tarp apibendrinamojo žodžio ir jị aiškinančių sakinio dalių yra ịsiterpęs jungiamasis žodis, pvz.:

(a) <...> żmagus krikszczioniszkas żiegnatus, użdiedamas ant sawies żinklu Kriżious Szwinta, ant ta gała, ira kożnay niedelay, pietnicziay pasnikas, tu pacziu pamini kasmietinie gawienie 40 dienu, a labiausi didieje niedele, mieti-nikie mukas Pona Jezusa, pamaksłeys, medytaciams ir numarinimeys $\langle\ldots>$. Balev 6. Otey ligas, iżgurdienimas turtu, priepoley wissakie, tey ira kriżieley, kurios mies kalti essim su linksmibi ir padiekawaimu prijmt', jegu gieydziem surinkt ażudarbi ant amżious giwienima. Balev 64. <..> iżgielbiek mani nog muku amżious pragara,_ arbo piekłes, <...>. Balev 70. Ligiej toki Izydoriaus junte dżaugsmu prie gału giwenima sawa, numanidamas jau arti wietu stebuklingu, taj ira dungu. Michnev 70. Tas tay ira katnas Aliwu, ant kuria Jezus naktims dażney mieldies. Balev 15. <...> tieykies jeszkoti, a nieturiunt ażugana ant tu wargu, kitaniszko łabious sapulingu kielu nog wietas paskutinia wieczeriaima Jerozolimska ling kałnuy Kalwarijas, biłay iżganima mana pakiełey <...>. Balev 10.

(b) Skajte iszmintingas knygas: gywenima ir stebukłus Kristuso Pono, grażius apraszimus swieto ir żemes. Akel 8. Turieje du sunu: wiena Jokuba asztąntą deszimti metu ejnąnti źita ir wobeli o antrą Tamosziu sekma deszimti bęngąnti. Val 52. Meldes be perstoima, spaude unt bur$n u$ ir unt szirdi sawa Kriżiu ir iszwajzdu Motinas Diewa, kałbedamas tas saldżiausius wardus: Jesus, Maryja, Josupas! Michnev 72.

(c) Diewas paseja unt juos auksa kwieczius, taj ira: matonie, ikwepimus ir doribes wisokia - bet welnias unt seja kukalu <...>. Michnev 56.

Kaip rodo pateikti pavyzdžiai, aiškinamosios sakinio dalys su jungiamaisiais žodžiais išskiriamos kableliais arba neskiriamos (a). Sakinio pabaigoje atskiriant vienarūšes aiškinamąsias sakinio dalis, einančias po apibendrinamojo žodžio, vartojamas dvitaškis (b). Daugianaris aiškinimas sakinio viduryje išskiriamas kableliu ir brūkšniu, o po jungiamojo žodžio rašomas dvitaškis (c). Apskritai pasakytina, kad šių sakinio dalių skyryba gana šiuolaikiška [plg. 6, 24-25]. 


\section{IŠVADOS}

Atlikta sisteminė vienarūšių ir aiškinamųjų sakinio dalių skyrybos duomenų analizė leidžia formuluoti šias įžvalgas:

1. Nuosekliausiai atskiriamos vienarūšès sakinio dalys, susietos bejungtukiu ryšiu. Pastebimas ryškus polinkis atskirti vienarūšes sakinio dalis, kai jas jungia priešpriešos jungtukai. Palyginti dėsningai nerašomas skyrybos ženklas tarp nekartojamais jungtukais sujungtų vienarūšių sakinio dalių. Dar nereguliari kartojamaisiais jungtukais sujungtų vienarūšių sakinio dalių skyryba.

2. Matyti tendencija išskirti aiškinamąsias sakinio dalis, pastebima nedidelè kablelio ir brūkšnio konkurencija esant tam pačiam skyrybos atvejui.

3. Išskirtinis M. Valančiaus nagrinėjamo teksto požymis - dažnesnis kabliataškio vartojimas. Čia jis turi stilistinès skyrybos bruožų - sakinio struktūrai suteikia savitumo, papildomų niuansų.

4. Palyginus originalių ir verstinių lietuviškų tekstų skyrybą, kokių nors ryškesnių skirtumų nenustatyta. Galima daryti prielaidą, kad verstinių tekstų autoriai galèjo nusižiūrèti i lenkiškus raštus ir vadovautis jų skyrybos principais. Tyrimą galètų papildyti verstinio teksto skyrybos lyginimas su originalu.

Gauta 20120420

Priimta 20120426

\section{Šaltiniai ir santrumpos}

Akel - AKELAITIS, Mikalojus. Kwestorius po Lietuwa ważinedamas žmonis bemokinasis. Wilniuja: spaustuweja A. H. Kirkora, 1860. 62 p.

Balev - BALEVIČIUS, Henrikas. Kielawiedis. Wilniuy: spaustuwiey J. Zawadzkia, 1857. 72 p.

Dovyd - DOVYDAITIS, Juozas Silvestras. Sziauleniszkis senelis. Pirma dalis. Wilniuja: spaustuweja J. Zawadzkia, $1863.61 \mathrm{p}$.

Michnev - MICHNEVIČIUS-MIKĖNAS, Kazimieras. Szwentas Izydorius artojas. Wilno: drukarnia A. Marcinowskia, 1859. 84 p.

Val _ VALANČIUS, Motiejus. Wajku kningiele su abrozdelejs: su abrozdelejs. Tilžej, 1868. 100 p.

\section{Literatūra}

[1] DRUKTEINIS, Albinas. Pertvarkytų skyrybos taisyklių taikymas. Gimtasis žodis, 2007, Nr. 12 (priedas), p. 2-10.

[2] KNIŪKŠTA, Pranas. Naujosios skyrybos taisyklès. Ka jos duoda ir ka patiems reikia suvokti. Kaunas: Šviesa, 2007. 39 p.

[3] Lietuviu kalbos enciklopedija. Red. V. Ambrazas. Vilnius: Mokslo ir enciklopedijų leidybos institutas, $1999.745 \mathrm{p}$.

[4] Lietuviu kalbos rašyba ir skyryba. 2-asis pataisytas fotografuotinis leidimas. Ats. red. A. Valeckienè. Vilnius: Mokslas, 1992. 263 p.

[5] PALIONIS, Jonas. Lietuviu rašomosios kalbos istorija. 2-asis pataisytas ir papildytas leidimas. Vilnius: Mokslo ir enciklopedijų l-kla, 1995. 335 p.

[6] Privalomosios ir pasirenkamosios skyrybos taisykles. Valstybinès lietuvių kalbos komisijos 2006 m. rugséjo 28 d. nutarimai Nr. N-2(103) ir Nr. N-3(104). Vilnius: Mokslo ir enciklopedijų leidybos institutas, 2006. $21 \mathrm{p}$.

[7] STATKEVIČIENE, Jadvyga. Praktine skyryba. Vilnius: Gimtasis žodis, 2003. 63 p. 
[8] ULVYDAS, Kazys. Dabartinès lietuvių literatūrinès kalbos skyrybos principai. Kalbos kultūra, 1963, sąs. 5, p. 3-16.

[9] VASILIAUSKIENĖ, Virginija. Lietuvių kalbos žodžiu tvarka XVI-XIX a. Atributinés frazés. Vilnius: Lietuvių kalbos institutas, 2008. 322 p.

\section{Use of punctuation marks in a simple sentence in the mid-19th century Lithuanian texts: homogeneous and explanatory parts of the sentence}

Summary

The studies of history of the Lithuanian language give only a general outline of the use of punctuation marks in the 16th-18th century texts. Systematic research of the development of punctuation of the Lithuanian language has been lacking to this day. No special studies have dealt with the punctuation of the mid-19th century Lithuanian texts. To determine the simple-sentence punctuation patterns in the written language of the period under discussion, original prose texts and translations by M. Akelaitis, J. S. Dovydaitis, M. Valančius, H. Balevičius and K. MichnevičiusMikènas were selected.

The systematic data analysis revealed that in the Lithuanian texts of the mid-19th century the punctuation of asyndetic homogeneous parts of the sentence is most consistent. There is a clear tendency to separate the homogeneous parts of the sentence when they are linked by adversative conjunctions. The omission of a punctuation mark between the homogeneous parts of the sentence linked by non-repetitive conjunctions is comparatively consistent. The punctuation of the homogeneous parts of the sentence connected by repetitive conjunctions is still rather irregular. There is a tendency to separate the explanatory parts of the sentence. A dash takes the position of a comma in the punctuation of the explanatory parts of the sentence. A semi-colon in the text by M. Valančius carries the signs of individuality and the features of stylistic punctuation.

The Lithuanian texts of the mid-19th century already witness the development of a more definite and consistent punctuation system, and the origins of standard punctuation can be observed (punctuation is very modern in quite a number of cases), even though fluctuations and variations are still rather common.

Key words: mid-19th century Lithuanian texts, punctuation, homogeneous parts of the sentence, explanatory parts of the sentence 